\title{
OUR ELDERS NEVER LIE: THE METAPHOR POWER \\ BASE OF PROVERBS AMONG THE TONGA \\ SPEAKING PEOPLE OF ZAMBIA AND ZIMBABWE
}

\author{
John Bwana Siakavuba \\ University of Zimbabwe \\ jobsia@yahoo.com
}

\begin{abstract}
This article seeks to explore ways through and extent to which the use of proverbs inspires confidence in the youth towards their elders in the African society in general and the Valley Tonga of Zambia and Zimbabwe in particular. The Achebean saying that 'proverbs are the palm oil with which words are eaten, 'does not only point to the fact that proverbs make ordinary speech aesthetically pleasant to the ear but also that the wisdom contained therein is culturally/socially accepted. The effective and efficient deployment of proverbs in this regard earns the user respect from targets of his address. The article analyses various ways in which proverbs are incorporated in everyday speech and how these in turn, enhance chances of delivering the intended message successfully among the Valley Tonga communicators. In most cases, when a Tonga speaker wishes to delegate presentation of a complex matter to the proverb, they attribute the wisdom to the Tonga society of yester years. This tendency, the article concludes, removes personalities from the proverb while promoting objective analysis of the situation by those addressed. The article examines selected proverbs in terms of structure, pattern of usage, types of images/metaphors used and their expected impact. The article applies a triangulation theoretical framework of Appraisal, Ethnopoetics and Afrocentricity theories to delineate the communicative intent of the proverber. Together, the theories look at social functions of the language rendered by performers of the oral arts.
\end{abstract}

Keywords: Proverbs, Paremiology, Metaphor, Tradition, Worldview, Agency, Communication, Negotiation, Elders, Valley Tonga, Afrocentricity, Appraisal, Ethnopoetics

\section{Introduction}

From as far back as the ancient Greeks when proverbs were recognised as a linguistic category (Haas, 2016), paremiologists have grappled with the challenge of coming up with a single universal definition, but to no avail. Mielder (1993:17) citing Taylor acknowledges the challenge when he says 'It is impossible to give the definition of a 
proverb.' However, different scholars have devised working definitions, such as a proverb 'could be conceptualised as any wise saying or epigram that converts the central idea in a given context, objectively and truthfully' (Mutunda, 2016: 512). Ngalande (2015:16) posits that 'proverbs are a rich collection of human experience.' On the other hand, Mandova and Chingombe (2013:10) feel that 'proverbs are condensed assertions about the shared experiences of a people in history over a period of time.' These truncations of the many floated global definitions of a proverb provide an absolutely smooth starting point for understanding paremiology. This article wishes to begin from the same general direction and proceed to draw specific leads from Wolfgang Mieder's (1993: 4) definition that:

A proverb is a short, generally, known sentence of the folk, which contains wisdom, truth, morals, and traditional views in a metaphorical, fixed and memorisable form and which is handed down from generation to generation.

The leads are '...contains truth, morals ... traditional views in a metaphorical ... form ....' What proverbs contain and the form in which they are given are the parameters of the interest of the current paper as it takes proverbs to be a special vehicle for transmission of thought intended to persuade the audience to accept it (thought) as a truth. The article seeks to examine the source of power or power base for proverbs that gives them that community sanctioned wisdom and authority. It is this community approved wisdom and authority that make elders never seem to lie because the younger generations see the used proverbs as representing absolute truth (Arora, 1984). The data was collected from experienced usage of proverbs witnessed during various stages of funeral rites among the Valley Tonga in the two districts of Binga and Sinazongwe on the Zimbabwean and Zambian sides, respectively. The data was collected using the ethnographic technique of immersion (Lewis1985, in Neuwenhuis, 2007) insulated from bias by the autoethnographic approach (Ellis, Adams and Bochner, 2011) since the researcher is a member of the performing community. Thus, the study keenly follows the intricate relationship that exists between the one who uses the proverb and the audience on one hand, and between these two and the context of the communication act on the other. It considers the experienced usage as a form of communication between the parties aimed at allowing the audience to experience the challenging situation to work out for themselves the implications and logic of the situation that has been tacitly presented through metaphor-laden language.

The study adopts the triangulation theoretical framework consisting mainly of the Appraisal theory, Afrocentricity and Ethnopoetics. The Appraisal spearheaded by Martin, (1997) and White, (1998) considers any communication event as an effort to negotiate meanings based on the speaker's opinion in relation to the issue at hand and to initiate and sustain relations with the audience. Domiciled in the linguistic area of discourse analysis, the Appraisal theory takes keen interest in the outcomes or impact of interactions of members of a community. The outcomes themselves, what Martin, (1997) and White, (1998) call affective, and rhetorical functionalities, respectively, are concerned with emotional responses and dispositions realised through mental processes of reaction that 
reflect individual convictions under cultural value systems of their community. Proverbs are such a communication platform whose impact is principal in this article and will benefit from the appraisal theory, which helps to determine the impact of their use in the given contexts as communication acts with intended outcomes by the one who uses them. Afrocentricity, on the other hand, means 'placing African ideals at the centre of any analysis that involves African culture and behaviour,' (Asante, 1998:2). The theory also propagated by Ani (1980) sees Africans (in this case the Valley Tonga) as the key players in activities of their own lives with a highly spiritual response to their environment at any given point in their history. Thus, the value of their experience is best accessed through their worldview. The theory helps in appreciating the metaphors from an African cultural perspective which rationalises the imagery, and 'emphasises the centrality of African agency, versatility and creativity in the interpretation of data relating to Africa and African people,' (Marongedze, 2019:17).

Similarly Ethnopoetics, conceptualised by Rothenberg, Tedlock and Hymes (1968, 1983 and 1996, respectively) is a theoretical apparatus which can be adopted for use in the study of proverbs. With its focus on the structure of oral performances and their characteristic elements of, among others, 'intonation contours, time expressions, quotatives, turns at talk, parallelisms, repetition ...,' (Hymes, 2003: 234), Ethnopoetics permits access to various ends that the art form, proverbs, are put to within the cultural and linguistic environments, making up what Dabaghi et al., (2010) refer to as the paroimía tradition, (of the Valley Tonga).

\section{Proverbs in the Context of Funeral Lore}

Proverbs often have no specialised occasions for their use, (Finnegan, 1970:394), neither are they restricted to any particular category of people. Their use is an integral part of everyday speech in human society and as Vansina (1985:27) states, 'they seem to evolve like any metaphor in the language.' As a matter of fact, proverbs generally, may even pass unrecognised as they blend very well with the words that constitute and sustain conversation. Rather, the use of proverbs is motivated more by issues being discussed as well as the speaker's experience. The issues of discussion themselves are also sponsored by the goings on at any given time which represent the nature and purpose of the speech event, the context. However, human verbal interaction is dominated by negotiation, persuasion, informing and enquiring, and proverbs play various influential roles in all these, such as diplomatic way of stating a hard truth, or giving authenticity or credibility to an argument.

Of course, in the process of servicing such purposes, proverbs have created space for abusive individuals or groups thereof, with malicious intentions. Many proverbs have put vulnerable sections of society at a disadvantage while promoting chauvinistic or exploitative schemes or even subversive or rebellious messages. Also, the indiscriminate use of proverbs has left the users a whole lifetime to restate their original and usually innocent intended messages. For example, Mutunda (2016) demonstrates how gender stereotype is constructed and reinforced within traditional Lunda society and the broader 
Zambian society. However, all the divergent uses which members of a community render proverbs to, notwithstanding, focus ought to also be placed on the discourse strategies and mechanisms that negotiate a proverb's meaning in a given context or interaction (Gumperz, 1982) because this is the basis for this article theoretical framework. Funerals merely provide the physical setting and occasion for people of various locations but akin in one way or another to come together.

Perhaps worth of mention here is the point that the Valley Tonga do not have formal coming of age institutions to initiate the young men and women into the adult world. They have always relied on the family, the village unit and the whole cisi (wider area in a chiefdom) for the socialisation of the young (Colson, 1960). Thus, they ultimately and optimally exploit any opportunity (including that offered by funerals) for social gathering of people of all ages to trade experiences, knowledge and attitudes. Among the Tonga people, especially of the Zambezi Valley, people stay together for the duration of the mourning period, which is determined in two phases - that of entombment and that of integration of the muzimu into ancestral spirits (mizimu), separation and incorporation, respectively. In the typical Valley Tonga setting, separation rites last five days with each day allocated a status marked by defined activities or rites. Day one is $l u f u$, denoting death - the day the death occurs and is characterised by emotional outbursts. Day two is mubila - the day dedicated to communicating or broadcasting the death. The third day is musozya, when the mourners are treated to the traditional snack of musozya - boiled whole maize grain. Day four is zipobwe when domestic meat animals like goats, sheep, cattle and even pigs are slaughtered to feed the mourners in a feast that may involve performance of chinyaanya, chilimba, and buntibe dances. Day five is kubukulula, when the bereaved family are left alone to hear the circumstances and implications of the death as well as brainstorm on the way forward. Also, it is on this day that clothes of the deceased are all brought out and either secured into a bundle for distribution to relatives during the next phase, or are given out to the relatives present there and then. This ends phase one of a Tonga funeral when the deceased's physical human being is separated from the world of the living.

Phase two is highly religious logical and seeks to convey the spirit of the deceased member of a family to the retinue of ancestral spirits. This article adopts the funeral of an adult member of the community in order to present the backdrop for discussion of the metaphor powerbase of proverbs among the Tonga people. This is because the funeral of an adult gives us the complete process of the incorporation phase. Essentially, this is because this phase may not be experienced in full for the death of a younger person - one who had not yet attained puberty. For an adult's funeral, phase two entails rituals leading to the incorporation of the deceased's spirit into the horde of family ancestral spirits. Such incorporation is marked by mapwayila which involves brewing beer that is consumed at a colourful ceremony following the cleansing rituals (kumana dilwe), and ritual drama of kutila performed at the graves. Major stages of this phase include kwaampa, the brewing process itself (five days for this), kwiinzya, kutila, kuzyana, kwaanga muzimu and kaboozyo. Kwaampa is the blessing of the grain to be used for masweezo (fermentation reagents) needed in the brewing process which progresses through the five stages; each 
lasting a day. These are kupalula, kujika, kukondola, koonena anze and kunywa. On the night of koonena anze, eve of the feast - cleansing (kwiinzya) takes place. Kutila (rites of offering the beer to the ancestors before it is served to the public), is performed in the morning on the day of the feast (kuzyana) before the actual feasting commences. The feast itself is characterised by performance of chinyaanya, cilimba and buntinbe. Indeed, as Muchemwa (2002:11) points out, 'The obsequies are celebrated with utmost grandeur and solemnity.'

During both phases of the full funeral process, there is no particular point dedicated to the performance of proverbs like it is with song and dance. Rather, proverbs come out as part of ordinary speech or other oral performances, such as song. This may occur at various instances during the entire mourning period. However, they may easily be found during the chitchats that take place in between or beside major events. For example, when the women folk are working on the funeral beer, men and elderly women would be busy with their crafts and chatting. It is during such windows that you hear the eloquence of idiom. During such occasions, too, younger members of the community are encouraged to hang around to carry out any tasks that may arise and of course, pick up some life skills from the elders. This is perhaps the only time when the younger and senior generations can sit together in one place at the same time without feeling out of place. It should be pointed out here that most of the proverbs used here can also be found in Mumpande's (2001) collection Tusimpi.

\section{Some Common Proverbs during Funeral Activities and their General Import}

A list of ten proverbs below recurred over and over at different funeral gatherings, and were used by different people. Their adoption for use here, should not in any way suggest that they are the most popular, let alone be taken to mean they are the best or that they are only used on such occasions. Rather, it is the total acceptance as truth their use received, especially by the youthful audience that attracted the interest of this study. Also, the manner in which the proverbs were used - with a sense of currency - did underscore their appropriateness for the study. Currency, as Mieder (1993) notes, is what renders proverbs evergreen, just as it supports analysis of how meaning is negotiated (Martin, 1997, White, 1998) and agency (Asante, 1998). Here, they are each presented with a literal translation and a contextual underlying meaning. Their morphological and metaphorical as well as philosophical analyses are given in the succeeding section.

Aalibapati taatiki musinza (literal translation: where there are elders, no broth spills). This proverb was used when encouraging a young man to speak out on the challenges he was facing in his new marriage so that the elders could assist should need be. One occasion of occurrence for the proverb was a funeral in the urban setting (Lusaka to be specific) while mourners were waiting for those who had gone to make burial arrangements to return and brief them. The young man was in a one and half year marriage but the couple had no child yet, neither were there signs of any coming soon. As the chitchat progressed on a variety of subjects, the young man's elderly cousin sneaked in the subject of childless marriages in a way of helping him receive help on the matter from the elders gathered. 
What the proverb means in this context is that sharing one's challenges with elders would not be in vain. In this case, an opportunity, identified by a sympathiser, to access the elders presented itself through the funeral gathering. The proverb is thus used whenever one is being encouraged to share whatever difficulties they were facing in life.

Simweenda alikke kakamutola kalonga (literal translation: He who travels alone was swept away by a brook). This proverb came out in the process of one respondent outlining the burial of an unidentified person. According to participant Nixon Muchoocha of Siampondo village in Zambia (July 2017), when an unknown person was discovered dead by the road side, he was buried there in a sitting position and his luggage kept by the headman of the community that buried him until his identity was established. Circumstances for such rare deaths would vary from attack by wild animals, especially snakes or escalated illness. The point of the proverb, then, is that when you travel alone people will never come to know what may cause your misfortune. The challenge in this proverb was ordinarily resolved by another which said ' $N g$ 'unu ng'unu ngwa babili', something like 'two is company', both of which discouraged lone trips. Another proverb which relates to the Simweend'alikke proverb is number g) below, 'Kwiindwa chuulu, maanda aabantu taayindwi.'

Mulandu tuuligwi lumoma/tuuboli (literal translation: A case is never eaten by termites/ white ants, or a case never decays). Usage of this proverb recurred at various funeral gatherings. In many instances, it came up during kubukulula, when outstanding issues affecting the deceased were brought up. Most of these related to the deceased being owed, the most common being marriage dues from sons-in-law. One occasion when it was not used in its natural context above is when an etiological narrative was used to demonstrate its origins. The tale cited a renowned young hunter, who, once failed to kill any game and ended up killing a sacred animal for fear of the shame he would face if he went back to the village without any game. When he arrived in the village, everyone was shocked and very disappointed with him for killing the sacred animal. No one celebrated his return the way they usually did. So, in frustration, he hung his kill on the fork of a tree and left the village for some unknown place where he stayed for many years. When he decided to come back he found the villagers in the same place and his kill of many, many years ago still up the tree and dripping fresh with blood just like it was when he left it. The old man who narrated the tale ended his account with the adage: 'mulandu tuuligwi lumomal tuuboli.'

Mweenzu usiya cisisi (literal translation: A visitor leaves a log of firewood). This is a proverb which hosts would use to acknowledge a contribution by their guest. Also, a guest can use it to assure the host that what he/she has done is not out of the ordinary. The proverb came out from time to time from both female and male group chitchats during funerals and speaks to the philosophy of being a useful guest.

Luya kwabo taluteyi mulenga (literal translation: The journey home is never too inhibiting). The proverb was mostly used by relatives who come to town for a funeral or indeed a casual visit to accost a town dweller who never visited the village on account of financial constraints or incapacitation. Such 'negligent' relatives may have abandoned their relations in the rural areas. It also serves as caution against remaining in foreign land even when things are hard and unbearable there. 
Joongolo teelyakabula kweenda akuulu kumwi kutawo (literal translation: A millipede never failed to move on because of one missing leg). The family is encouraged to move on despite the demise of a member or indeed the absence of one member. This is common at the time of kubukulula dilwe or kwaambula twambo (discussing funeral issues). The proverb can also be heard at burial and at the time of kunjila mung'anda as well as other times when mourners need encouragement to move on despite the bereavement. The adage is also heard when deliberations stall due to the absence of a member.

Kwiindwa cuulu, maanda aabantu tuuyindwi (literal translation: An anthill may be by passed, not a people's homestead). The proverb encourages individuals to always announce his presence in every village he passes through on his journey. It came out during narration of how unidentified deceased men were buried in faraway lands where death found them. When one does this, the people through whose village they passed would have an idea who they were, where they were coming from, where they were headed to and so on. In the event that such a traveller met his death on the way, his identity would easily be established, his remains repatriated and his family would accord him a normal burial with all funeral rites observed.

Ng'ombe tyoka tubone nkuwaakazwida (literal translation: Stray/lost cow, break your leg so that we know where you come from). One may appear kinless but their relatives will appear as soon as he/she gets into trouble. It cautions, especially husbands, against abusing their wives because they are assumed to have no close relatives to stand for them in the areas where they are married.

Siakali milandu itema uuli mwida (literal translation: A case today will be committed by one that is yet to be born or is still in the womb). This is a caution to people to beware that an offence against another family will not die and can be avenged by members of future generations. This proverb was a rare one but it came out when, at a funeral, people were discussing the motive of a strange hardness on what everyone considered a straightforward and relatively light case. The aggrieved party came out very strongly and demanded a rather unfair compensation. It took the memory of an elderly member of the community to explain the genesis of that attitude when the plaintiff's team had gone to consult among themselves regarding the apparent stalemate. The elderly man revealed that in the early 1960s, all the village cattle grazed together and a member of the aggrieved family, this time around, had been accused by a member of the defendant in the present case of breaking the leg of an ox belonging to one of the village members and the case was determined against the then accused. None of the two people involved in that earlier case were present as they were both old people working in faraway places. In fact, the accused in the current case was a grandson (in the context of the matrilineal family system) to the prosecution witness of the earlier case, making the whole situation perfect for the proverb. When the consultations were over and the group rejoined the gathering, a member of the family in defence used the proverb by way of stating that despite the saying, the current case did not deserve that degree of sternness. Apparently, the other camp had also shared the experience of many decades ago and had resolved to lower the compensation they were asking for. Later, when the grandfather of the accused in the latter case was asked 
about the case of long ago, he confirmed his own mother (now long dead) had warned through the proverb that revenge on the matter should be expected on generations to come.

Kaluba mwaambi, mwaambilwa talubi (literal translation: It is usually easily forgotten by the one who says it but not the one told). In an event where accusations and counter accusations are levelled against one another and denied, respectively, the proverb has come out strongly to convince the accused that they actually said what they are denying. In most cases, the denied statements turn out to be true as those who heard them being uttered insist on the validity of the claims. In a way, it is a caution against careless talk about others or indeed making ridiculous or unrealistic promises.

\section{The Morphology and Syntax of the Tonga Proverb}

As Ngalande (2015:414) observes, many proverbs 'are in bipartite structure,' comprising a norminalised subject and a predicate. Rarely do we find stand-alone nouns functioning as subject of the whole proverb except as that of the compounded subject in the proverbs, although in cases like ' $N g$ 'ombe tyoka, tubone nkuwakazwida', (proverb number h, above), a noun would serve as subject of the norminalised subject. Quite clearly here, 'Ng'ombe tyoka', is the compounded subject in which the noun, Ngombe is its subject, yet the whole $-\mathrm{Ng}$ 'ombe tyoka - is the compounded subject for the proverb. Such occurrence is also notable in 'Joongolo teelyakabula kweenda akuulu kumwi kutawo.' Nonetheless, in proverbs (d) 'Mweenzu ...,' and (c) 'Mulandu, ...'we see nouns standing alone and serving as complete subjects for the proverbs where they feature in this article.

It is also a common feature of the Tonga proverbs to pronorminalise the subject using the class 1 subject maker (Ngalande, 2015:13), si/sia as in 'Siakali milandu' (i), 'Simweenda alikke ...' (b). In the same vein, there are found the adverbial nominals forming the subject of proverbs like 'Kwiindwa cuulu ...' (g) or 'Aalibapati ...' (a).

What is worth noting here is that these linguistic characteristics serve a deliberate, if not rhetorical function to emphatically foreground the metaphors at play. The bipartite arrangement further allows proverbs to be easily remembered and become participative in nature. Because, when invoked, a proverb will automatically challenge the audience to complete it ahead of the one that employs it. Thus, the subject is enough to bring the audience to supply the predicate and hence, confirm that the communication is progressing well. Besides, the manner in which the proverbs are launched in a conversation among the Tonga speaking people points to the involvement of the whole tradition. The precursor to the proverb is always a disclaimer attributing the proverb to the entire ethnicity and not the individual employing it - 'Bansiku/bensiku bakati ...,' (Our ancestors said ....) This factor allows Scheub's (1977) scheme of the expansible image in which he demonstrates that the incorporation of idiom, proverb, song, or such other aspects of speech are treated as extensions that transfer delivery of the message to themselves and thus, constitute a form that spares the main text from extensive elaboration as it, at the same time, functions to delegate completion of interpretation of the situation at hand to the audience via such extensions. In this case, the metaphor of the proverb, as Steen (2007:49) points out, 'is not merely a linguistic but also a conceptual phenomenon, a figure of thought.' Through 
their allusiveness, therefore, proverbs achieve what no amount of words would be able to accomplish. However, while this may be so, some scholars have raised concerns that the trend has capacity to relegate the status of proverbs to clichés; yet as Haas (2016) rightly argues, proverbs do not have the linguistic chamelionism which clichés are believed to be adept at.

\section{Metaphorical and Philosophical Meaning of the Proverbs}

The thesis that 'our elders never lie' arises from two basic principles around proverbs: that they contain common truths about society; and that they speak candidly to expectations of their audience on account of relying on shared imagery for ultimate interpretation. As Jack Lee cited by Mutunda (2016: 511), observes, 'proverbs are the mirror of culture in that they can reflect the customs, traditions, values, opinions and beliefs of a particular society.' Lakoff and Johnson (1980:5) aptly elucidate the latter principle as 'understanding and experiencing one kind of a thing in terms of another.' This perspective suggests that in order for the deployed proverb to carry impact, there must be dualistic harmony between what Maslova and Minakhin (2018) refer to as metaphorical field and metaphorical world, wherein field points to the real image and world to the imagined one. It is in this comparison of images that a given proverb derives its ultimate impact in delivering the interpretation of a situation and arresting the audience's confidence in the speech event. Thus, the communicative nature of the proverb relies heavily on how familiar or remote the two images are to the audience. It is appealing to argue that the discovery of interconnectedness of the imagined image to the real one is the one that gives the audience that sense of pleasure at the use of the proverb and hence, appreciation of its use in that particular context or situation. To the audience, the pleasure arises from the understanding that the user of the proverb has confidence as to how familiar the real image in the used proverb is based on the audience's perceived familiarity with the environmental or consequent or even resulting imagined images. Thus, the relationship between the two is not a one on one affair but more of a 'many-to-one set of emotional allusions' to use Spencer's (2019: 5) words. Such a position is grounded in the cognitive grammar argument that metaphoric imagery is found within the common environment of the user and the audience, and has the ability to represent the deep, unexpected sense of the word in special forms (Lakoff and Johnson, 1980, Maslova, 2016).

Using the foregoing as the linguistic pedestal for discussing the metaphor powerbase of proverbs, let us now turn to the imagery in each one of the primary texts that constitute the basis for forming the meaning out of which sense is derived. The distinction between meaning and sense in literary texts is aptly detailed in Maslova's (2016) write up, but suffice to say meaning is 'the starting point for the formation of new and individual senses while sense is a collection of many ideas and associations that arise in our minds' out of the used words' (p. 436). The opening parts of all the proverbs Aalibapati (where there are elders), Simweend'alikke' (He who travels alone), 'Mulandu' (A case), 'Mweenzu' (A visitor), 'Luya kwabo' (The journey leading home), 'Joongolo' (millipede), 'Kwiindwa cuulu' (An anthill may be passed), 'Ng'ombe tyoka' (Cow break your leg), 'Siakali 
milandu' (A case today), and 'Kaluba mwaambi' (That which can be forgotten by one who says it), contain fixed images that anyone who understands the language is able to recognise This is because they mainly state facts which do not refer to any out of the ordinary conjectures. This part, therefore, provides the concrete slab upon which the brick wall is laid in terms of contextualising the proverb. All the proverb predicates sit on this slab from which their underlying meaning and sense are seen.

Content of the predicates is what provides the inherent wisdom in the proverbs and thus, forms the basis for considering them as aesthetic expressions. For example, while the presence of elders in 'Aali bapati taatiki musinza,' one would wonder as to why, out of all possible endings, the proverb opts for musinza (broth). Why use the image of musinza for advice? To get the full import of the metaphor, we need to go well beyond the immediate environment and get to intergenerational levels. Broth which Scudder (1971:20) describes as 'a tasty soup into which chunks of relatively tasteless porridge (nsima) are dipped,' is part of cisyu/buyani (relish) and makes a significant part of the main meal in many African cultures, and is associated with meat accompaniments to the staple food, nsima among the Tonga people. It is the component responsible for the ultimate enjoyment of a meal, be it among elders or young people, as it supplements the quantities of saliva required for mastication and initial digestion of solid foods. Thus, it is a well understood substance which plays a critical role in the diet of these people. In this regard, to state that musinza will not spill where elders are, underscores the importance rendered to it in the Tonga food culture such that it should not be spilt anyhow. It, therefore, takes this kind of background to appreciate the imagery of musinza and associate it with wisdom which elders are credited with. This is the level of agency that proponents of the Afrocentricity theory (Ani, Asante) perceive African art with. Removed from this agency, the meaning of the proverbs can easily be lost because all the imagery and allusions are constructed from a cultural position, (Finnegan, 1970).

In a similar manner, we can consider the idea of kalonga (translated here as brook) sweeping away someone as a metaphor that points to the fact that when one is alone, he or she is so vulnerable as to be swept away or to be drowned by the simplest water bodies. Again, for full appreciation of the metaphor, one needs to beseech the landscape of what we may call Tongaland. For example, the Tonga people of Zambia and Zimbabwe from whom the proverbs were collected are those found in the Zambezi Valley. As has been pointed out by many scholars such as Colson (1957, 1960, 1970), Scudder (1971), and others, the Zambezi Valley is characterised by mountainous terrain with multitudes of such streams that race down the valley directly into the Zambezi or any of its tributaries. These do not normally pose a threat to anyone, but to emphasise the importance of the need for company, they are given capacity to sweep one away. Thus, even if one did not see the underlying meaning of the proverb, they are given somewhere to start from in that imagery. The same applies to Mulandu tuuligwi lumoma. We know lumoma (termites/ white ants) to attack organic stuff such as wood and stalks of food crops like maize, millet, sorghum, bulrush millet and such other weed like plants. To associate white ants with a case or offence clearly requires the interpreter to go beyond the natural objects 
into the phenomenological conceptualisation. Whereas everyone would be expected to understand what mulandu (case/offence) is, imagining that it can never be obliterated or removed by the lumoma which is known to be so stubborn through the way it shreds physical objects like wood and even synthetic materials like canvas underscores the inviolability of a mulandu, which can only be disposed of by discussion and not walking out or indeed passage of time. This is further cemented by the etiological narrative that was used to illustrate the possibility in dramatic form.

Furthermore, the Tonga have found yet other significant imagery in the product of another variety of white ants, the termites - cuulu - or anthill to adopt in their search for creative expression of great wisdom. Cuulu is a common feature of the African savannah landscape, which anyone can ignore as a non-human creation of little consequence. One who notices but ignores a human settlement in the same way he would ignore cuulu is being admonished in the proverb 'Kwiindwa cuulu maanda aabantu tayindwi,' to think twice and recognise that in life, every human being is important to the wellbeing or activities of the other or others. This proverb derives its cognitive powers from the fact that when you stop over to greet people, you are first of all announcing your presence in that neighbourhood and making your mission known. Secondly, you are seeking counsel from the people who know their neighbourhood regarding your safety on the route you are following in your journey. Seen in the way the proverb was rendered into perspective, should anything happen to you, by way of kutolwa kalonga people from the last village through which you passed if you interacted with them will help trace you to your next of kin so that these take over attending to your needs. We can also learn from the proverb, albeit in a subtle manner, the people's attitude towards ecoprotection - do not disturb natural phenomena like the anthill.

All, if not most of the ending parts or predicates of Tonga proverbs use conceptualisations that exist way out of the ordinary happenings. However, these are not farfetched. They are drawn from people's immediate environment, landscape, traditions, food culture, customs, etiquette and language as well as belief systems. A good visitor is one that joins the hosts in their chores, hence, Mweenzu usiya cisisi. And why cisisi of all things? Firewood is a basic necessity among many rural communities as it symbolises fire and the warmth it provides. Furthermore, the place of fire in society is equivalent to life because all major foods are cooked on fire before being served for consumption. In this light, therefore, cisisi is a life supporting item and one who contributes such an item is considered worthy of hosting. On the other hand, the concept of no place is better than home finds itself deployed in the proverb 'Luya kwabo taluteyi lulenga.' Clearly, no one will be reluctant to go back home among the Tonga people, let alone any other, world over. Even in death, the Tonga would rather they were buried in their home village. As a matter of fact, the point of resistance to relocation at the time of actualising the economic project of Kariba dam was the idea of being removed from the resting place of one's ancestors to some unknown places. In this regard, Mwindaace N. Siamwiza (nd.: i) shared the following testimony: 
When this fact of abandoning our ancestral lands became a reality, anger gave way to utter despair. It is not easy to describe the despair. Suffice to say that my paternal grandmother Buyuni willed herself to death because she could not contemplate burial [outwith] the lands of her ancestors. She died in August 1958, a month or two before my village Mulungwa, was moved to its present site. Buyuni now lies several hundred metres below the waters of Lake Kariba, content to be beside her ancestors. As for me, I have yet to accept Mulungwa as my home in spite of the forty intervening years.

There are many other testimonies about how the Valley Tonga regard home especially in the light of the relocation which occurred in 1958. These are available in other publications like 'Our gods never helped us again,': Oral Testimonies, and The People of the Great River (Thomson, 2005 and Tremmel, 1994, respectively). However, while conditions are no longer supportive of everyone's desire to be buried among their ancestors, to the extent that people can now be buried wherever death finds them, all the funeral rites have continued to be concluded in the home village by family elders. So, despite the challenges one is facing, the journey back home is unstoppable. When opportunity to travel back to the village avails itself, all one needs is the spiritual drive or will and the way will be found.

In the same vein, the Tonga family system is so elaborate that there will never be a time when one will have no one to represent him as family. The matrilineal family system which the Tonga people follow has made it so robust that the absence of a single member can never derail its intentions and aspirations. The proverb referring to the millipede is a very precise representation of the Tonga family system with its many legs signifying the infinite structure of the Tonga family establishment. Thus, the indisposition or incapacitation of an individual member should not warrant a shutdown of operations. It also serves as a reminder to the individual members never to contemplate considering themselves more important than others so as to hold any family processes at ransom. Anyone who boycotts any stage of a family event will eventually find a replacement or could eventually be ignored as there is no crisis of participants of a particular family role. In the context of this article, even the feeblest of creatures, joongolo, in the immediate environment of the performing community is recognised to possess features that help magnify their philosophical viewpoints and intellections.

The Tonga wherever they are found, be it on the Zambian or Zimbabwean side are an agricultural community highly dependent on cattle for tilling the land, fertilising the fields, provision of nutrition through milk and occasionally, beef, transport and many other by-products and services. When an animal strays into a herd, the host villager into whose herd it strays knows too well that it is not his but for the period it will stay, it will contribute to the manure and is, therefore, not in a hurry to look for the owner. The owner of such a cow, on the other hand, is also confident that wherever his animal has strayed to, it is safe and will one day be retrieved. Such an animal could stay away from its owner for as long as it takes. However, the day it will get hurt, the owners will show up and 
claim it. This has presented a very powerful image that when all is well, no one needs to claim ownership. Thus, claiming ownership at this stage is actually taking responsibility. Meanwhile, the proverb 'Ng'ombe tyoka tukuzibe nkuwakazwida' is a reminder to people that there is nothing in this world that has no owner and that anyone can act caretaker on behalf of the real owner who may only surface when things go wrong. This awareness is the inert motivation for the humility, hospitality and loving nature associated with the Tonga people. By deploying a central cultural item, ing'ombe, the proverb urges people to take care of other people's property as if it was their own in the same way theirs may also be taken care of by others. This, notwithstanding, the proverb reminds all that should anything go wrong, the real owner will be expected to show up, also pointing to the fact that issues of an individual's security and ill health are superintended by the next of kin. On the other hand, it can be seen as a subtle but effective way of discouraging people from abusing things that are not theirs including public property, or even against stealing because in it is the underlying fact that everything has an owner. This connotes a powerful moral vital in governance.

The last two proverbs in this study, Siakali milandu and Kaluba mwaambi, both share some polemic commonality, yet, of course, they refer to totally unrelated circumstances. While the former refers to a situation where a case committed by one generation may be avenged by generations yet to come, the latter refers to how what the mouth utters stays in the memory of those to whom it is directed regardless of the time it might take. While the idea of time is common to both, vengeance under collective family memory and individual recollection, respectively, separate them. However, both appeal to the ethos of the need to be aware of critical developments in the family and individual life which might recur in future. The metaphor of 'uuli mwida' (the yet to be born) and 'mwaambilwa' are both drawn not from the physical environment but out of linguistic epistemologies that form nouns from behaviour related attributes of the people involved. 'Siakali milandu' alludes to how family histories are passed from generation to generation such that future generations are fully aware of the challenges their ancestors experienced and have the responsibility to deal with them when the time is ripe. This, then points to the need for keeping family histories live among generations so that they are not lost with the passage of time. This is particularly important to the lives of primary communalities whose only repositories for historical information are oral traditions. Thus, members of such societies are encouraged to share common histories as well as take interest in learning these from the community.

In the case of 'Kaluba mwaambi', the point of caution is that one should seriously consider implications of whatever they say whether under the spur of the moment or in earnest as spoken words leave a deeper imprint in the minds of the audience than in the one who utters them. Often times, out of anger or excitement, one can issue threats or make commitments which stay in the minds of the audience. However, to discern the ultimate meaning from the proverbs whenever they are employed requires deep audience reflection. The underlying messages challenge the utterer of the original words who now becomes the audience to realise that it is important to make responsible pronouncements as these will always be tagged on them as the case is in 'Kaluba mwaambi'. 
In 'Siakali milandu,' it would be a warning to either party to pay attention to family histories because the present mirrors the past just as much as the past will influence the future. It is the use of this particular proverb that furnished the current study with its main title. The elders of the aggrieved camp accepted the argument by their opponents that despite the validity of the proverb, there was no justification to charge so much for the case at hand. This turn of tides, made the younger members of the community present to realise that indeed, their elders always spoke the truth. The resolution of this matter also points to the dynamic nature of life. While the ethos of society are upheld, the wind of change in application of these is not without reason, hence, the decision to abandon the route of vengeance, while keeping track of the oral heritage.

While there are all these various persuasive messages in the proverbs tackling specific life departments of the Tonga people, the Buntunyina philosophy pulsates through all of them. The philosophy going through the sub region of Southern Africa under the term Ubuntu,

... is a social philosophy which embodies virtues that celebrate the mutual social responsibility, mutual assistance, trust, sharing, unselfishness, selfreliance, caring and respect for others among other ethical values, (Mandova and Chigombe, 2013: 100)

The spirit of sharing, caring for one another, unselfishness and all the other virtues of Ubuntu resound persistently through all the proverbs which have characterised the lives of the African society as a whole and the Tonga people in particular, and have been passed on as a powerful heritage from generation to generation. This is what defines the African.

\section{Conclusion}

This article has been concerned with Tonga proverbs as a genre of oral funeral performances, especially in the way they appeal to members of that community. Much as the Tonga people are found in other parts of both Zambia and Zimbabwe, the material in the article was collected from the Zambezi Valley, particularly Sinazongwe and Binga districts in the respective countries. The article was on the sidelines of one in the same catchment area on oral funeral performances which proverbs are part of. The main focus of the article is where the proverbs draw their impetus from for them to capture the praise of the youth for their elders. As a linguistic rendition, proverbs have been presented in this article as compositions with a bipartite structure comprising two parts serving functions of subject and predicate, respectively. In addition, the study has observed that the metaphors that power the proverbs are drawn from the immediate environment of the Tonga people the landscape, values systems, morals and etiquette, food culture, agriculture, wildlife, family as well as societal histories, and many other spheres of their life. This is all for the purpose of creating a common platform from which to generate common interpretations of the imagery. The article observes that two assumptions keep both the user and target of the proverbs in close fellowship: that the user assumes his audience is familiar with the proverb and that the audience have capacity to interpret the imagery in the context of the 
case at hand. This binding force plays a very critical role in unpacking the complicated situation at hand and is reinforced by attributing the proverb to the whole paroimia tradition and wisdom of the Tonga people rather than the individual. In addition, it is the considered view of this article that true sense and meaning of thoughts presented in a people's cultural expressive milieu is best discerned through that people's looking glasses. The study has also hopefully triggered more interest in paremiology by demonstrating that proverbs are not limited in their offer to academia as they have both positive and negative applications to those who wish to use them. Ours has been to explore the confidence proverbs inspire in the younger generations when positively used.

\section{References}

Ani, M. (1980). Let the Circle Be Unbroken. New York: Nkonimfo Publications.

Arora, S.L. (1984). The Perception of Proverbiality, in Mieder, W. (ed.). Wise Words: Essays on the Proverb. New York: Garland. 3 - 29.

Asante, M.K. (2007). An Afrocentric Manifesto: Toward an African Reinessance. Cambridge: Polity Press.

Asante, M.K. (1998). The Afrocentric Idea. Philadelphia: The Temple University Press.

Dabaghi, A., Pishbin, E., and Niknasab, I. (2010). 'Proverbs from the Viewpoint of Translation.' Journal of Language Teaching and Research, 1(6), 807-814.

Ellis, C., Adams, T.E. and Bochner, A.P. (2011). Autoethnography: An Overview, Forum Qualitative Social Research Sozialforschung. [Online]. 12(1). Available: http:// www.qualitative-research.net/index.php/fqs/article/view/1589/3095 [2011, January].

Finnegan, R. (1970). Oral Literature in Africa. Oxford: Oxford University Press.

Gumperz, J.J. (1982). Discourse Strategies. Cambridge: Cambridge University Press.

Haas, H.A. (2016). 'Are Proverbs Cliché? An Application of the Elaboration Likelihood Model to Folkloric Performance.' Proverbium 33: 193 - 242.

Hymes, D. (2003). Now I Know Only So Far: Essays in Ethnopoetics. Lincoln: University of Nebraska Press.

Hymes, D. (1996). Ethnography, Linguistics, Narrative Inequality: Toward an Understanding of Voice. London: Taylor and Francis.

Hymes, D. (1981). 'In Vain I Tried to Tell You': Essays in Native American Ethnopoetics. London: University of Nebraska Press.

Lakoff, G., and Johnson, M. (1980). Metaphors We Live By. Chicago: Chicago University Press.

Mandova, E., and Chigombe, A. (2013). 'The Shona Proverb as an Expression of UNHU/ UBUNTU.' International Journal of Academic Research in Progressive Education and Development. January 2013, 2(1): 100 - 108.

Martin, J.R. (1997). Analysing Genre: Functional Parameters, in Christie, F., and Martin, J.R. (eds.). Genres and Institutions: Social Processes in the Workplace and School. London: Cassell. 3 - 39. 
Marongedze, R. (2019). Interface of Music and Politics: Versions of Patriotic Consciousness in Zimbabwean Music, 1970 - 2015. Unpublished Doctoral Thesis. University of South Africa: Pretoria.

Maslova, Z., and Minakhin, D. (2018). Metaphor and Metaphorical Worlds: A Cognitive -Ontological Approach, [Online]. Available: www.academia.edu/39499388/.

Maslova, Z. (2016). Meaning, Sense and Informativity in Metaphoric Language. Biljana Mišić Ilić/Vesna Lopičić. Conference Presentations: UDC 81'373.612.2:159.955: 429 $-444$.

Mielder, W. (2004). Proverbs - A Handbook. Westport: Greenwood Press.

Mieder, W. (1993). Proverbs Are Never out of Season: Popular Wisdom in the Modern Age. Oxford: Oxford University Press.

Muchemwa, B. (2002). Death and Burial among the Shona: The Christian Celebration of Death and Burial in the Context of Inculturation in Shona Culture. Harare: Pastoral Centre.

Muchoocha, N. (2017). Personal Interview. 11 July, Village Siampondo, Chief Mweemba, Sinazongwe District, Zambia.

Mumpande, I. (2001). Tusimpi: Tonga Proverbs Harare: Silvera House.

Mutunda, S. (2016). 'Portrayal of Women in Folklore: A Case Study of Proverbs Among the Lunda in North Western Part of Zambia.' International Journal of English Language, Literature and Humanities (JELLH), IV (II): 508 - 527.

Neuman, W.L.(2000). Social Research Methods: Qualitative and Quantitative Approaches. Boston: Allyn and Bacon.

Ngalande, S. (2015). Nsenga Proverbs in Zambia: Linguistic, Ethnographic and Logical Analyses. Kyoto: Shoukadoh Book Sellers.

Nieuwenhuis, J. (2007). 'Qualitative Research Designs and Data Gathering Techniques,' in Mares, K. (ed.). First Steps in Research. Pretoria: Van Schaik Publishers. 70 - 97.

Scheub, H. (1977). 'The Technique of the Expansible Image in Xosa Nsomi-Performance,' in Lindfors, B. (ed.). Forms of Folklore in Africa: Narrative, Poetic, Gnomic, Dramatic. Austin: University of Texas pp $37-63$.

Siamwiza, M.N. nd. Foreword in Zaucha, G. Batonga Across the Waters: A Travelling Exhibition of the Batonga of Zambia and Zimbabwe Forty Years After the Building of the Kariba Dam. Choma: Choma Museum: i.

Spencer, H.J. (2019). TOO RADICAL: A Positive Review/Essay of 'Philosophy in the Flesh' by George Lakoff and Mark Johnson (1999) [Online]. Available: http://www. academia.edu. 9.3 Kw. [14February2019].

Thomson, E. (2005). 'Our Gods Never Helped us Again.' : Oral Testimonies. London: Panos Southern Africa.

Steen, G.J. (2007). Finding Metaphor in Grammar Usage: A Methodical Analysis of Theory and Research. Amsterdam: John Benjamin Publishing. 
Tremmel, M., and the River Tonga People. (1994). The People of the Great River: The Tonga Hoped the Water Would Follow Them. Gweru; Mambo Press.

Vansina, J. (1985). Oral Tradition as History. Wisconsin: The University of Wisconsin Press.

White, P.R. (1998). Telling Media Tales: The News Story as Rhetoric. Unpublished Doctoral Thesis. University of Sydney: Sydney. 